\title{
Effectiveness of Fartlek Training on Maximum Oxygen Consumption in Young Obese Females- An Experimental Study
}

\author{
Namrata Krishnat Patil ${ }^{1}$, Archana $\mathrm{Methe}^{2}$, Drashti Shah ${ }^{3}$, Ronald Prabhakar ${ }^{4}$ \\ ${ }^{1}$ B.P.Th. Intern, Miraj Medical Center, College of Physiotherapy, Wanless Hospital. Miraj. Maharashtra, India \\ ${ }^{2,3}$ Assistant Professor, Miraj Medical Center, College of Physiotherapy, Wanless Hospital. Miraj. Maharashtra, \\ India \\ ${ }^{4}$ Professor, Miraj Medical Center, College of Physiotherapy, Wanless Hospital. Miraj. Maharashtra, India
}

Corresponding Author: Namrata Krishnat Patil

\begin{abstract}
Background: Obesity is accumulation of excessive fat in adipose tissue due to which endurance is decreased leading to negative impact on cardiovascular endurance. The prevalence of obesity in females is more than in males that is $44.7 \%$. Obesity leads to decrease in endurance and thus negative impact on cardiovascular endurance. VO2max is common measure of cardiopulmonary fitness. Endurance training leads to increased mitochondrial activity which decreases lactic acid accumulation at given VO2 and improving performance by enhancing fat oxidation. Fartlek training is a speed play which leads to improve the endurance capacity. Thus this study was aimed to find the effectiveness of Fartlek training on maximum oxygen consumption in young obese females.

Material and Methodology: 30 subjects with obesity class I $(n=30)$ were selected in this study, with age group 18-25 years based on inclusion and exclusion criteria with their consent. Fartlek training was given 4 days per week for 5 weeks. Queens College step test was used to assess the pre and post effects of the training.

Results: Fartlek training showed significant effect on maximum oxygen consumption. Mean pre queens college step test of young obese females receiving Fartlek training was 39.2. Mean post queens college step test for the same was 42.2. The mean difference pre and post queens college step up test is zero $(\mathrm{p}=0.000)$.
\end{abstract}

Conclusion: The study concluded that there was significant effect of Fartlek training on maximum oxygen consumption in young obese females.

Keywords: Obesity, young females, Cardiovascular endurance, Fartlek training, Queens College step test.

\section{INTRODUCTION}

World Health Organization defines obesity as a condition of excessive or abnormal accumulation of fat in adipose tissue, the extent that health may be impaired ${ }^{[1]}$. Prevalence of obesity in India is $44.7 \%$ among women and among adults with age group of $20-40 y r s$ is $72.9 \%$, compared with male population women are more probable to be overweight and obese ${ }^{[2]}$. Almost $29.6 \%$ females have abdominal obesity $^{[3]}$. The rapid increase in number of individuals who are overweight and obese that is with excess of adiposity is now recognized as one of today's leading threat to health and a major risk factor for type 2 diabetes, cardiovascular disease, and hypertension ${ }^{[4]}$. Obesity leads to decrease in endurance and thus negative impact on cardiovascular endurance. In obesity increase in skinfold measurement correlates significantly with absolute maximal oxygen 
uptake throughout the range of body fat levels, and oxygen consumption per kilogram of body weight and treadmill endurance time both declined as fatness increased. Obesity did not affect maximal walking economy. All of these indicate that increase in fat levels associates with increased cardiopulmonary exercise capacity, but that functional fitness declines because of inert load created by excess body fat $^{[5]}$.

Body mass index is a metric is the metric used to define anthropometric height/weight characteristics in adults and to classify them in groups ${ }^{[6]}$. Body mass index is calculated as weight in kilogram divided by the square of height in meters $\left(\mathrm{kg} / \mathrm{m}^{2}\right)$, according to NHLBI.

Table1. BMI Asian-pacific classification of Nutritional status. \begin{tabular}{|l|l} 
NUTRITIONAL STATUS & BMI $\left(\mathrm{kg} / \mathrm{m}^{2}\right)$
\end{tabular}

\begin{tabular}{|l|l|}
\hline UNDERWEIGHT & $<18.5$ \\
\hline NORMAL RANGE & $18.5-22.9$ \\
\hline OVERWEIGHT & $23-24.9$ \\
\hline OBESE-I & $25-29.9$ \\
\hline OBESE-II & $>30$ \\
\hline
\end{tabular}

According to conventional WHO classification: Obesity: $B M I>30$ $\mathrm{kg} / \mathrm{m} 2$, Overweight: BMI 23.1-29.9 kg/m2, Normal: BMI 18.5-23 $\mathrm{kg} / \mathrm{m}^{2}[7]$.

Fartlek is meant as a speed play. This method of training is combination of continuous training with interval training. Fartlek can be defined as period of fast running intermixed with a period of slower running. It can be jogging with sprinting or walking with jogging or brisk walking. The vary of intensity and continuous nature of exercise places stress on both aerobic and anaerobic systems. Fartlek training is form of a road running in which the participant varies the pace significantly during the run ${ }^{[8]}$. Fartlek training can be planned in any manner as per subject's endurance capacity. Unstructured protocol of Fartlek can be used for beginners. Aerobic, anaerobic and anaerobic system gets activated due to fluctuation in intensity and pace. A Fartlek's session can be done in groups the subject can keep improving by accelerating the pace and replacing the earlier protocol for progression ${ }^{[9]}$.
Maximal oxygen uptake refers to oxygen consumption of a subject when exercising as hard as possible for that subject. A fit and healthy young adult should be able to achieve a vo2max of about $37.85+4.3 \mathrm{ml} / \mathrm{kg} / \mathrm{min}$ for female subject [10]. Maximum oxygen consumption is limited by the ability of cardiorespiratory system to provide oxygen to the working muscles ${ }^{[11]}$. The three major lines of evidence are, if the oxygen delivery is altered then maximum oxygen consumption changes according to it, the increase in maximum oxygen consumption with training results mainly from maximal cardiac output increase, when a small muscle mass is over perfused while exercising then it has a very high capacity for consuming oxygen. Thus, oxygen delivery and not skeletal muscle oxygen extraction, is viewed as the main limiting factor for maximum oxygen consumption is exercising human being. Endurance training leads to increased mitochondrial activity which decreases lactic acid accumulation at given $\mathrm{VO} 2$ and improving performance by enhancing fat oxidation [11]. Vo2max is commonly used is exercise physiology as a measure of cardiopulmonary fitness.

Studies have shown that Maximum oxygen consumption is reduced due to obesity as there is decreased body metabolism. In few studies that are done on athletes for assessing respiratory function showed to have almost normal maximum oxygen consumption, but when Fartlek training was applied to the group of participants it proved to have significant effect on maximum oxygen consumption. Studies have shown that VO2 max is reduced in obese population. There are lack of evidence that show effect of Fartlek training in non-athletic young population. There are fewer literatures that have shown effect of Fartlek training on maximum oxygen consumption in obese population; hence this study is being conducted.

The aim of the study is to study the effectiveness of Fartlek training on maximum oxygen consumption in young 
obese females. The practice of physical activities is widely recommended for obese individuals as they have increased risk of decreased cardiovascular endurance thus the objective of the study was to evaluate the effectiveness of Fartlek training on maximum oxygen consumption in young obese females

\section{MATERIALS AND METHODS}

30 obese females from undergraduate colleges in Miraj, Maharashtra, India voluntarily participated in the study. Participants with age group of 18-25 years, Obese females with BMI- 25 to $29.9 \mathrm{~kg} / \mathrm{m}^{2}$ and with no history of smoking were included in the study. The exclusion criteria were subjects with cardio respiratory co-morbidities. Neurological, Metabolic or musculoskeletal disorders and Subjects not willing to participate Ethical approval was obtained from the Institutional Ethical Committee. The procedure was explained to the subjects in their vernacular language. Informed consent was obtained from the participants and has voluntarily participated in the study. Demographic data was obtained (name, age, gender, Body Mass Index (BMI), address) and detailed assessment was performed using VO2max. Pre- VO2max was calculated by Queen's College Step Up Test. Further, subjects were given Fartlek Training for 4 days per week for 5 weeks and post- VO2max was calculated. Data was formatted in tabular format and were further statistically analysed.

\section{Procedure}

\section{FRATLEK TRAINING PROTOCOL:}

Subjects those matching the inclusion criteria with age group of $18-25$ with obesity I from 25 to $29.9 \mathrm{~kg} / \mathrm{m}^{2}$ Body Mass Index range were included for the study The subjects were asked to perform all the prescribed number of repetition and sets as prescribed in the scheduled. The details of work period, number of repetitions and sets, recovery between repetitions and sets are presented below.

Table2.TRAINING SCHEDULE: [FOR 5 WEEKS, 4 DAYS PER WEEK]

\begin{tabular}{|c|c|c|c|c|c|c|c|}
\hline WEEK & $\begin{array}{l}\text { WARM } \\
\text { UP }\end{array}$ & $\begin{array}{l}\text { WORK } \\
\text { PERIOD }\end{array}$ & $\begin{array}{l}\text { NUMBER OF } \\
\text { REPETITIONS }\end{array}$ & $\begin{array}{lr}\text { ACTIVE } & \text { RECOVERY } \\
\text { PERIOD } & \text { BETWEEN } \\
\text { REPETITIONS } \\
\end{array}$ & $\begin{array}{l}\text { NUMBER } \\
\text { OF SETS }\end{array}$ & $\begin{array}{l}\text { RECOVERY } \\
\text { BETWEEN } \\
\text { SETS } \\
\end{array}$ & $\begin{array}{l}\text { COOL } \\
\text { DOWN }\end{array}$ \\
\hline I \& II & $10 \mathrm{MIN}$ & 25 & 7 & $\begin{array}{l}120 \quad \text { SEC DECREASE } \\
\text { WITH } 20 \text { SEC }\end{array}$ & 3 & $2 \mathrm{MIN}$ & $10 \mathrm{MIN}$ \\
\hline $\begin{array}{l}\text { III \& } \\
\text { IV }\end{array}$ & $10 \mathrm{MIN}$ & 25 & 7 & $\begin{array}{l}90 \quad \text { SEC DECREASE } \\
\text { WITH } 15 \text { SEC }\end{array}$ & 3 & $2 \mathrm{MIN}$ & $10 \mathrm{MIN}$ \\
\hline $\mathrm{V}$ & $10 \mathrm{MIN}$ & 30 & 7 & $\begin{array}{l}120 \quad \text { SEC DECREASE } \\
\text { WITH } 20 \text { SEC }\end{array}$ & 3 & $2 \mathrm{MIN}$ & $10 \mathrm{MIN}$ \\
\hline
\end{tabular}

The training protocol included warm up exercise for 10 minutes, the total work period was for 25 minutes, Fartlek training was given to the subjects with 7 repetition, if subject felt tired walking was initiated and as the fatigue was recovered jogging, running, sprinting was performed. The active recovery period between each repetition for I and II week was $120 \mathrm{sec}$ which was decreased by $20 \mathrm{sec}$ after each repetitions. Foe week III and IV it was 90 sec and was decreased by $15 \mathrm{sec}$ and for week V it was $120 \mathrm{sec}$ and decrease with 20 sec. 3 sets were given to each subject with 2 minutes of recovery between each set. Later at the end of the protocol cool down exercise for 10 minutes.

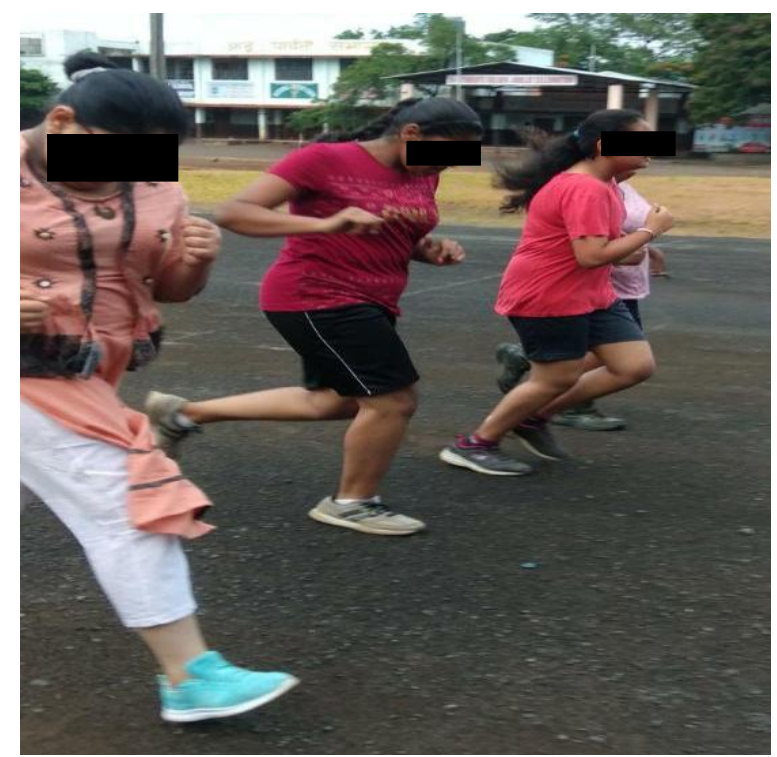

Fig 1. Fartlek training 


\section{OUTCOME MEASURE:-}

\section{QUEENS COLLEGE STEP UP TEST}

- This test is used to asses VO2max.

- Maximum Oxygen Consumption Queens college step test -reliability= 0.92 -validity $=-0.75$

- In, females this test is performed for 3 mins. During which, they should complete 22 steps in 1 min by doing Step up and down (in 4 step cadence i.e. UP-UP; DOWN- DOWN).

- Heart rate was measured at radial pulse before \& after test.

- Formula to calculate VO2max in Females:

- VO2 $\max (\mathrm{ml} / \mathrm{kg} / \mathrm{min})=65.8-[0.1847$ multiplies by heart rate (bpm) ${ }^{[12]}$.

- Further, these values were added to the formula.

- Equipments used: Weighing scale, Stadiometer, Stopwatch, Metronome application and a 15 inch step

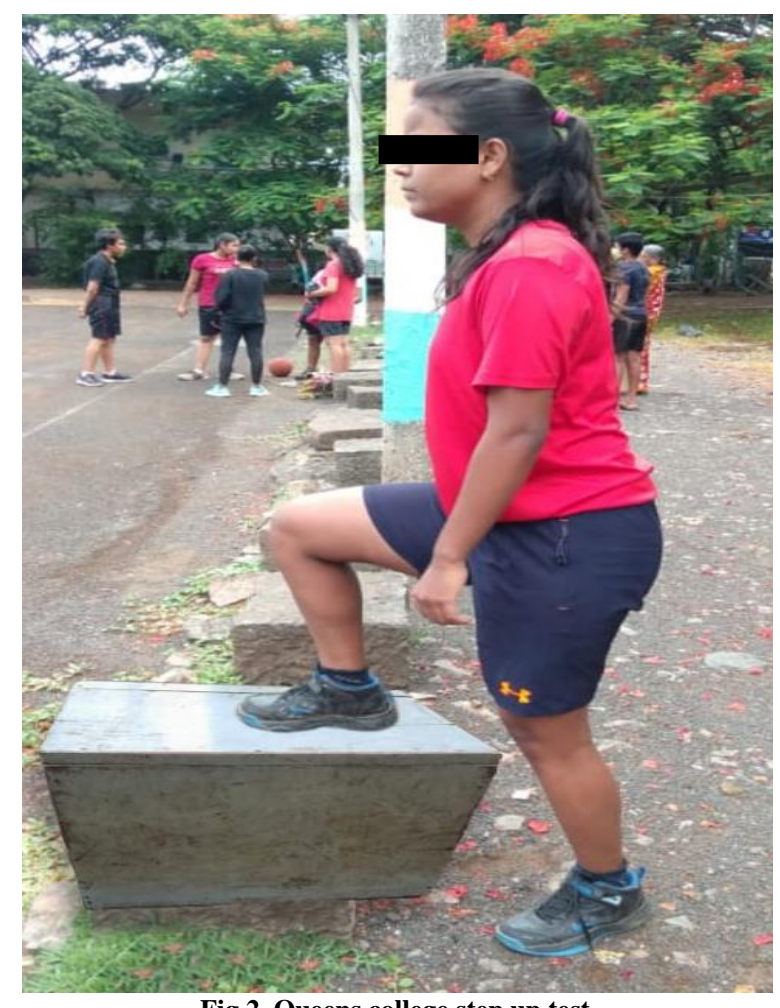

Fig 2. Queens college step up test

\section{Statistical Analysis}

All statistical analysis was done by Statistical Package for the Social Sciences
(SPSS) Version 16.0 for windows. Wilcoxon Signed Ranked Test was performed for intragroup scores. $\mathrm{p}=0.05$ was the set significance level. Descriptive analysis was used for calculation of mean and standard deviation.

\section{RESULT}

Pre and post intervention values of Queens College Step Up Test in young obese females receiving Fartlek Training were analysed using Wilcoxon Signed Ranked Test as shown below.

Table 3. Demographic Data

\begin{tabular}{|l|l|l|l|l|}
\hline Variable (n=30) & Max & Min & mean & Std. Dev \\
\hline Age (years) & 25 & 18 & 21.7 & 1.4 \\
\hline Height(meters) & 1.7 & 1.4 & 1.5 & 0.05 \\
\hline Weight (kg) & 82 & 58 & 69.7 & 5.9 \\
\hline BMI & 29.9 & 25.1 & 27.5 & 1.6 \\
\hline
\end{tabular}

Table 3. represent the mean age, height, weight, and BMI (demographic data) of young obese females which were included in this study.

The subjects participated in Fartlek Training which were obese young females had excellent significant post intervention in Queens College Step Up Test score (0.000) which is shown in Table 4.

Table 4: pre and post intervention values of Queens College Step Up Test

\begin{tabular}{|l|l|l|l|}
\hline Variable $(\mathbf{n}=\mathbf{3 0})$ & mean & Std. Dev & P value \\
\hline Pre treatment & 39.2 & 1.00 & \\
\hline Post treatment & 42.2 & 1.76 & 0.000 \\
\hline
\end{tabular}

The mean difference pre and post queens college step up test is zero also $p$ value is 0.000 which is less than $5 \%$ level of significance, thus alternative hypothesis significant effect of Fartlek training on maximum oxygen consumption in young obese females is accepted.

\section{DISCUSSION}

The study aims to determine effectiveness of Fartlek training on maximum oxygen consumption on young obese females. The subjects in this study had similar baseline values of height, weight, age and BMI. This study was conducted on 30 subjects with age group of 
18-25 years young obese females having BMI of $25-29.9 \mathrm{~kg} / \mathrm{m} 2$. Pre vo2 max was assessed using queens college step test further Fartlek training was given for 4 days per week for 5 week and posttest was done using queens' college step test. The results of the study revealed that at the end of 5 weeks the vo2 max of the participants was seen to be statistically improved.

According to the previous studies obesity leads to decreased in endurance leading to negative impact on cardiovascular endurance, the fitness declines due to inert load created by excess body fat ${ }^{[5]}$. Obesity is leading threat to health and major risk factor for type 2 diabetes, cardiovascular disease and hypertension ${ }^{[4]}$.

The relative risks among the obese individuals for overall death, the cause of death coronary heart disease, and cardiovascular disease are $1.22,1.57$, and 1.48 , respectively, when compared with those within the lowest BMI category. ${ }^{[19]}$. Oxygen demand of the skeletal muscle is directly proportional to cardiorespiratory reponse because as physical activity is performed heart rate linearly increases ${ }^{[20]}$.

Studies have shown that Maximum oxygen consumption is reduced due to obesity as there is decreased body metabolism. Studies done by Anjali N Shete studied that the body fat percentage affects VO2 max. The aerobic capacity of athletes is an important element of success in sports, as it is the best indicator of cardio respiratory endurance. Their study was undertaken to assess the VO2 max and body fat percentage in female athletes and nonathletes of age group 17-22 years. The results showed the mean VO2 max in athletic group was $39.62 \pm 2.80 \mathrm{ml} / \mathrm{kg} / \mathrm{min}$ and non-athletic group was $23.54 \pm 3.26$ $\mathrm{ml} / \mathrm{kg} / \mathrm{min}^{[18]}$. The results suggest that the maximum oxygen consumption was lower in non-athletic population than in athletics.

Studies done by Mansi Shingala and Yagna Shukla aimed to find out effectiveness of Fartlek training on cardiorespiratory fitness and muscular endurance in young adults. They concluded that Fartlek was statistically significantly effective in improving the cardiorespiratory fitness and muscular endurance in young adults. Exercise intensity must stimulate the increase in stroke volume and cardiac output and enhance the aerobic metabolism and local circulation in appropriate muscle group. For adaptation to occur the period of exercise must be within person's tolerance above the threshold level ${ }^{[15]}$.

Exercise affects almost all systems of the body and their adaptations reflect on improvement on vo2 max. During the active recovery of Fartlek training, increase in vo2 max occurs due to a portion of muscular stores of ATP and the oxygen associated with myoglobin that depletes during the work period are replenished by the aerobic system ${ }^{[16]}$. The continuous nature with varying intensity of Fartlek exercise places stress on aerobic and anaerobic systems, this kind exercise shows result in shorter time because more calories are consumed after exercise completion ${ }^{[17]}$.

The advantage of Fartlek training is that no specialised equipment is needed and can be performed as one wish to due to its flexibility and it can be performed at any pace by the individuals by their own. Due to obesity sprinting fast running throughout is not so easy thus the Fartlek training is beneficial and effective.

\section{CONCLUSION}

According to the findings of the study it was concluded that Fartlek training improved the maximum oxygen consumption and has significant effect in obese females. The limitations of the study are that only young obese females were included and prolonged effect of Fartlek training on maximum oxygen was not assessed.

Further, research can be carried out with a broader margin of age group with large population. 


\section{ACKNOWLEDGEMENT}

I take this wonderful opportunity to thank all the "HANDS" which have joined together to make this project a SUCCESS.

It's my great pleasure and privilege to express my deep-felt gratitude to our respected Principal sir Dr. Ronald Prabhakar and Guide Dr. Archana Methe who immensely helped me and rendered their advice, precious time, constant encouragement, knowledge and relevant information regarding my study, and whose suggestion and guidance has enlightened me on this subject. I am also great full to Dr. Amit Nagrale Professor dept. Of community medicine, Miraj Medical Centre, College of physiotherapy, Wanless Hospital, for help in the data analysis of this study. I express my sincere thanks to all the teaching $\&$ nonteaching staff of the Miraj Medical Centre, College of Physiotherapy.

I would thank my subjects for participating in my study. Above all, I would like to thank my parents for their blessings, love, constant support, affection and encouragement.

Praise and Glory to the God Almighty who is the source of strength, foundation of my knowledge and the source of inspiration in every walk of life.

\section{Conflict of Interest: None}

\section{Source of Funding: None}

\section{Ethical Approval: Approved}

\section{REFERENCES}

1. World health organization, obesity: preventing and managing the global epidemic, WHO consultation on obesity (1999: Geneva, Switzerland)

2. Bindhu AK, Jose RP, Beevi N. Prevalence of obesity and overweight among adults in a rural area in Trivandrum: a cross sectional study. Int J Prev Ther Med. 2014 Apr;2.

3. ZAR A, KARAN KP, AHMADI MA. Prevalence of obesity and overweight among female students of Shiraz University of Medical Sciences and its association with physical fitness factors. Commonity Health .2017, 4(2); 79-89.

4. Engerman SL, Gallman RE, editors. Longterm factors in American economic growth. University of Chicago Press; 2007 Nov 1.

5. Rowland TW. Effects of obesity on aerobic fitness in adolescent females. American Journal of Diseases of Children. 1991 Jul 1;145(7):757-62

6. Nuttall FQ. Body mass index: obesity, BMI, and health: a critical review. Nutrition today. 2015 May;50(3):117

7. Lim JU, Lee JH, Kim JS, Hwang YI, Kim TH, Lim SY, Yoo KH, Jung KS, Kim YK, Rhee CK. Comparison of World Health Organization and Asia-Pacific body mass index classifications in COPD patients. International journal of chronic obstructive pulmonary disease. 2017; 12:2465.

8. Kumar P. Effect of Fartlek training for developing endurance ability among athletes. International Journal of Physical Education, Sports and Health. 2015;2:291-3.

9. Pradeep Kumar. Effects of Fartleks training for developing endurance ability among athletes. International Journal of Physical Education, Sports and Health. 2015;2(2): 291-293.

10. Nabi T, Rafiq N, Qayoom O. Assessment of cardiovascular fitness [VO2 max] among medical students by Queens College step test. Int J Biomed Adv Res. 2015;6(5):41821.

11. Bassett DR, Howley ET. Limiting factors for maximum oxygen uptake and determinants of endurance performance. Medicine and science in sports and exercise. 2000 Jan 1;32 (1):70-84.

12. Gossard D, Haskell WL, et.al. Effects of low-and high-intensity home-based exercise training on functional capacity in healthy middle-aged men. The American journal of cardiology. 1986 Feb 15;57(6):446-9.

13. Katona PG, McLean MA,. Sympathetic and parasympathetic cardiac control in athletes and nonathletes at rest. Journal of Applied Physiology. 1982 Jun 1;52 (6):1652-7.

14. Hickson RC, Hagberg JM, et.al. Time course of the adaptive responses of aerobic power and heart rate to training. Medicine and science in sports and exercise. 1981; 13(1):17-20.

15. Shingala M, Shukla Y. Effectiveness of Fartlek Training on Cardiorespiratory Fitness and Muscular Endurance in Young 
Namrata Krishnat Patil et.al. Effectiveness of fartlek training on maximum oxygen consumption in young obese females- an experimental study.

Adults: A Randomized Control Trial. IJPOT. 2019 Apr;13(2):86.

16. Kisner C., Colby L. Therapeutic exercise Foundation and Techniques. Margaret Biblis. $5^{\text {th }}$ edition.

17. McArdle W., Katch F \& Katch V. Exercise physiology. Wolters Kluwar and Lippincott Williams \&Wilkins. $7^{\text {th }}$ edition, ch. 21 , pg. 483

18. Shete AN, Bute SS, Deshmukh PR. A study of $\mathrm{VO} 2$ max and body fat percentage in female athletes. Journal of clinical and diagnostic research: JCDR. 2014 Dec;8(12):BC01.

19. McGee DL, Diverse Populations Collaboration. Body mass index and mortality: a meta-analysis based on personlevel data from twenty-six observational studies. Annals of epidemiology. 2005 Feb 1;15(2):87-97.

20. Byrne NM, Hills AP. Relationships between $\mathrm{HR}$ and VO2 in the obese. Medicine \& Science in Sports \& Exercise. 2002 Sep 1;34(9):1419-27.

How to cite this article: Patil NK, Methe A, Shah D et.al. Effectiveness of Fartlek training on maximum oxygen consumption in young obese females- an experimental study. Int $J$ Health Sci Res. 2021; 11(7): 37-43. DOI: https://doi.org/10.52403/ijhsr.20210706 